\title{
A study on perinatal outcomes in antenatal mothers with abnormal pulmonary function tests
}

\author{
Subha Sivagami Sengodan ${ }^{1 *}$, Anandheeswari Palanivelu², Anbarasi Pandian
}

\begin{abstract}
${ }^{1}$ Department of Obstetrics and Gynaecology, ${ }^{2}$ Department of Thoracic Medicine, Government Mohan Kumaramangalam Medical College, Salem, Tamil Nadu, India
\end{abstract}

Received: 18 April 2018

Accepted: 23 May 2018

\section{*Correspondence:}

Dr. Subha Sivagami Sengodan,

E-mail: drppsamysubha@gmail.com

Copyright: ( $)$ the author(s), publisher and licensee Medip Academy. This is an open-access article distributed under the terms of the Creative Commons Attribution Non-Commercial License, which permits unrestricted non-commercial use, distribution, and reproduction in any medium, provided the original work is properly cited.

\begin{abstract}
Background: This study was done to assess the lung volumes by spirometry in all the three trimesters in antenatal mothers and to observe the effect of pulmonary function abnormality in mode of delivery and birth weight of babies.

Methods: Our study included 100 antenatal mothers attending antenatal clinic in Government Mohan Kumaramangalam Medical College, Salem, Tamil Nadu during the period of Jan 2017 to Dec 2017. It was a prospective observational study. Mothers were subjected to detailed physical and clinical examination. Basic investigations were done. Considering test by spirometry. The changes in the lung volumes were noted according to gestational age. The effect of pulmonary function abnormality in the mode of delivery and birth weight was observed. Results: One hundred antenatal mothers selected randomly were evaluated for the lung volumes by using spirometry. Out of the 100 cases, 17 belonged to I trimester, 46 belonged to II trimester and 37 belonged to III trimester. We noted a significant reduction in FVC in II and III trimester. This reduction was little more in II trimester. There was significant reduction in FEV1 in II trimester. The reduction in FEV1 and FVC did not influence the mode of delivery but it significantly affected the birth weight of babies. FEV1/FVC reduction had no influence in the mode of delivery and birth weight of babies.

Conclusions: The present study highlighted that there was reduction in lung volumes in II and III trimester of pregnancy and it influenced the birth weight of babies. Hence it becomes essential to pay special attention to pulmonary functions during antenatal period.
\end{abstract}

Keywords: Antenatal mothers, Birth weight, Mode of delivery, Pulmonary function test

\section{INTRODUCTION}

During pregnancy due to increasing demands of the growing foetus, there occurs many changes in the maternal body. These changes are not only related to the maternal genital organs but they do occur in different systems of the body. In pregnancy the hormonal changes that takes place, affects the upper respiratory tract and airway mucosa. This leads to hyperaemia, mucosal oedema, hyper secretion and increased mucosal friability. Anatomical changes during pregnancy like cephalad displacement of diaphragm increases the anteroposterior and transverse diameter of thorax, increase in sub costal angle occurs due to expansion of uterus. ${ }^{1,2}$ These changes are maximum during 28-31 weeks of pregnancy and they become normal within 6 months after delivery. Due to these changes the lung volumes get altered but not compromised during pregnancy. ${ }^{3}$

Aims and objectives of present study were to assess the lung volumes in different trimesters of pregnancy using spirometry and to determine the effect of gestational age 
on the pulmonary functions of pregnant mother, to determine the perinatal outcome i.e., mode of delivery and birth weight of the baby based on pulmonary function abnormality.

\section{METHODS}

This prospective observational study was conducted in Government Mohan Kumaramangalam Medical College, a tertiary care hospital, Salem, Tamilnadu, India during Jan 2017 to Dec 2017. We included 100 antenatal mothers attending antenatal clinic in our hospital. Informed written consent was obtained from all of them. Detailed history was taken, thorough physical examination and basic blood investigations were done before performing the spirometry. Based on the lung function abnormalities the mode of delivery, birth weight of babies was analysed using the SPSS 10 software.

\section{Inclusion criteria}

Mothers attending our Obstetrics and Gynaecology op.

\section{Exclusion criteria}

Mothers with heart diseases, pulmonary tuberculosis, pulmonary artery hypertension, systemic hypertension, diabetes mellitus, lung abscess, pneumonia, asthma on bronchodilators, twin pregnancy.

\section{RESULTS}

Table 1: Distribution of antenatal mothers according to age.

\begin{tabular}{|lll|}
\hline Age (in yrs) & Frequency & Percentage \\
\hline $17-21$ & 54 & 54 \\
\hline $22-26$ & 35 & 35 \\
\hline $27-31$ & 9 & 9 \\
\hline $32-36$ & 2 & 2 \\
\hline
\end{tabular}

In the present study $54 \%$ of mothers belonged to $17-21$ yrs, $35 \%$ belonged to $22-26 \mathrm{yrs}, 9 \%$ belonged to $27-31$ yrs and 2\% belonged to 32-36 yrs. More number of mothers belonged to the age group of 17-21 yrs (54\%). Only $2 \%$ of mothers belonged to $32-36$ yrs.

Table 2: Number of antenatal mothers with abnormal lung functions in various trimesters of pregnancy.

\begin{tabular}{|llll|}
\hline $\begin{array}{l}\text { Lung } \\
\text { volume }\end{array}$ & I Trimester & $\begin{array}{l}\text { II } \\
\text { Trimester }\end{array}$ & III \\
FEV1 & 0 & 3 & 3 \\
\hline FVC & 1 & 5 & 4 \\
\hline FEV1/FVC & 0 & 0 & 1 \\
\hline
\end{tabular}

Out of the 100 antenatal mothers, 6 mothers showed decrease in FEV1. 3 cases in II trimester and 3 cases in III trimester. This decrease in FEV1 was insignificant with $\mathrm{P}$ value of 0.46 . Among the 100 mothers 10 mothers showed decrease in FVC. This decrease was more in II trimester. But this change was insignificant with $\mathrm{P}$ value of 0.56 . Among the 100 antenatal mothers only 1 case showed reduced FEV1/ FVC. This change is insignificant with a $P$ value of 0.49 .

Table 3: Mode of delivery in abnormal lung function antenatal mothers.

\begin{tabular}{|llll|}
\hline $\begin{array}{l}\text { Lung } \\
\text { function }\end{array}$ & Preterm & LSCS & $\begin{array}{l}\text { Normal } \\
\text { delivery }\end{array}$ \\
\hline FEV1 & 0 & 4 & 2 \\
\hline FVC & 0 & 5 & 5 \\
\hline FEV1/FVC & 0 & 1 & 0 \\
\hline
\end{tabular}

Among the 100 antenatal mothers, 62 mothers underwent LSCS. Out of the 62 mothers who underwent LSCS, 4 mothers had reduced FEV1. This showed that the value of FEV1 on mode of delivery was insignificant with $\mathrm{P}$ value of 0.9 . Out of the 100 antenatal mothers, 10 mothers had reduced FVC. Among the 62 mothers who underwent LSCS, 5 mothers had reduced FVC, which showed that the of FVC was insignificant on the mode of delivery with the $\mathrm{P}$ value of 0.89 . Out of 100 antenatal mothers, 1 mother had reduced FEV1/FVC. Among the 62 mothers who underwent LSCS, 1 mothers had reduced FEV1/FVC, which showed that of FEV1/FVC was insignificant on the mode of delivery with the $\mathrm{P}$ value of 0.7 .

Table 4: Birth weight in abnormal lung function antenatal mothers.

\begin{tabular}{|lll|}
\hline Lung volumes & $\begin{array}{l}\text { Low birth } \\
\text { weight }\end{array}$ & $\begin{array}{l}\text { Normal birth } \\
\text { weight }\end{array}$ \\
\hline FEV1 & 4 & 2 \\
\hline FVC & 4 & 6 \\
\hline FEV1/FVC & 0 & 1 \\
\hline
\end{tabular}

Out of the 10 antenatal mothers with reduced FVC, 4 mothers delivered babies with low birth weight $(<2.5$ $\mathrm{kgs}$ ). This showed that there is a significant effect of FVC on birth weight of babies with a $\mathrm{P}$ value of 0.04 . Out of the 6 antenatal mothers with reduced FEV1, 4 mothers delivered babies with low birth weight $(<2.5 \mathrm{kgs})$. This showed that there is a significant effect of FEV1 on birth weight of babies with a $\mathrm{P}$ value of 0.01.Among 100 antenatal mothers 1 mother showed reduced FEV1/FVC and she gave birth to normal weight baby. This showed that there is no effect of FEV1/FVC on the birth weight of babies with a $\mathrm{P}$ value of 0.6 which is insignificant.

\section{DISCUSSION}

The physiological changes that occur during pregnancy related to respiration (breathing, lung volumes and lung capacities) are due to hormonal changes and mechanical factors that occur during pregnancy. ${ }^{4}$ In our study we 
analysed the changes in pulmonary functions (FEV1, FVC, FEV1/FVC) and their influence on mode of delivery and birth weight of babies. In our study, there is decrease in FEV1 during pregnancy. But this decrease is insignificant with respect to mode of delivery. Our study is correlating with Sulata Mahapatra et al study. In our study, with increase in gestational age there is decrease in FVC. This decrease is more in II trimester of pregnancy but is insignificant with respect to mode of delivery. Our study is correlating with Sulata Mahapatra et al study. Our study is against to the study of Ameet et al which showed no difference in FVC and Grindheim et al which showed increase in FVC in II trimester of pregnancy. ${ }^{5,6} \mathrm{~A}$ decrease in FEV1 and FVC was observed was observed in our study which correlates with Neeraj et al study. ${ }^{7}$ Our study does not correlate with Dudhmal et al study which showed non significant increase in FEV1 and FVC during pregnancy. ${ }^{8}$ In our study the decrease in FEV1 affected the birth weight of babies with significant $P$ value of $<0.05$. In Ameet et al study there is no difference in FEV1 and FVC. Jadhav et al in his study found that there was a significant decline in FVC and FEV1. ${ }^{9}$ Enlargement of gravid uterus can cause restrictive effect on lungs. Reduction in alveolar partial pressure of $\mathrm{CO}_{2}$ during pregnancy leads to bronchial smooth muscle constriction and can lead to airway obstruction. Airway resistance is dependent on lung volume. The reduction in lung volumes can lead to increase in airway resistance. The hormones secreted during pregnancy (progesterone, corticosteroids and relaxin) have been implicated in the reduction of resistance and increase in the conduction in the respiratory pathway.In M. Schatz RS Zeiger, CP Hoffman et al study the perinatal outcomes in women with effectively managed asthma during pregnancy had no significant effect on the incidence of pre-eclapsia, IUGR, preterm birth and LBW babies. ${ }^{10}$ The same study found that the decrease in pulmonary function during pregnancy was associated with increase in gestational hypertension, premature labour. In Gustaf et al study showed that there was an association between maternal asthma and increases risk of pregnancy complications preeclampsia, eclampsia, preterm labour, emergency LSCS, LBW. ${ }^{11}$ It also showed that the incidence of these complications were more in uncontrolled asthmatic antenatal mothers.

Our present study highlights that the respiratory parameters are significantly compromised due to the gravid state of uterus with increase in gestational age in Indian mothers. We feel to establish norms on predicted and desired PFT values in pregnant mothers in various trimester of pregnancy.

In our study, we selected 100 antenatal mothers attending antenatal clinic and pulmonary function tests were done using spirometry. The results were analysed with respect to gestational age and the effect of changes in lung volumes on the mode of delivery and birth weight of babies. In our study the effect of FEV1 and FVC on birth weight of babies was significant. The FEV1, FVC,
FEV1/FVC showed a decrease with increase in gestational age. As lung functions are affected during pregnancy and which accordingly determines the birth weight of babies, it is necessary to pay attention to pulmonary functions during the antenatal period. Pulmonary breathing exercises like deep inspiration and expiraton increases utero placental circulation decreases the placental insufficiency which increases the birth weight of babies.

\section{CONCLUSION}

Findings noted in our study are:

- There is decrease in FEV1, FVC, FEV1/FVC with increase in duration of pregnancy.

- The decrease in FEV1, FVC effected the birth weight of babies.

During pregnancy progesterone, corticosteroids and relaxin causes smooth muscle relaxation and bronchodilation. The mechanical disadvantage caused to the respiratory system by advancing pregnancy is compensated by decrease in airway resistance and an improved airway conductance. Though there are changes in lung functions during pregnancy, the overall maternal respiratory functions remain unaffected.

\section{Funding: No funding sources}

Conflict of interest: None declared

Ethical approval: The study was approved by the Institutional Ethics Committee

\section{REFERENCES}

1. Jadhav S, Dudhamal VB, Karadkhedkar SS, Afroz S, Razvi NA. Comparative study of pulmonary function tests on different trimesters of pregnancy. Int J Cur Res Rev. 2013;5(2):118-22.

2. Santhakumari U, Umayal CC, Gunavathy G. A pulmonary function test in pregnancy-A cross sectional study study. Int J Curr Res. 2015;7(7):17926-9.

3. Shailaja Y, Srikanth S. Lung function tests in different trimesters of pregnancy. Indian $\mathrm{J}$ Basic Appl Med Res. 2013;3(1):285-92.

4. Mohapatra S, Satapathy U, Panda N. Study of Pulmonary Function Tests During Pregnancy At Physiological Variable Conditions. J Med Sci Clin Res. 2017;5(5):21795-800.

5. Fadia A, Dhadse M. A comparative study of dynamic pulmonary function tests in Indian pregnant and nonpregnant women. Int J Med Sci Public Health. 2016;5(10):2114-7.

6. Grindheim G, Toska K, Estensen ME, Rosseland LA. Changes in pulmonary function during pregnancy: a longitudinal cohort study. BJOG. 2012;119(1):94-101..

7. Neeraj Candy S, Pramod J, Singh J, Kaur V. Effect of advanced uncomplicated pregnancy on pulmonary 
function parameters of north Indian subjects. Indian $\mathbf{J}$ PhysiolPharmacol. 2010;54(1):69-72.

8. Dudhamal B, Dudhamal VB, Parate S. Study of pulmonary function test in different trimester of pregnancy. Int J Med Res Rev. 2015;3(10):2321-734.

9. Chinko BC, Green KI. Peak expiratory flow rate of pregnant women in port Harcourt. Int Res J Med Sci. 2014;2(6):1-5.

10. Schatz M, Dombrowski MP, Wise R, Momirova V, Landon M, Mabie W, et al. Spirometry is related to perinatal outcomes in the pregnancy of asthmatic women. A prospective study. Am J Obstet Gynecol. 2006;194(1):120-6.
11. Rejnö G, Lundholm C, Gong T, Larsson K, Saltvedt $\mathrm{S}$, Almqvist C. Asthma during pregnancy in a population based study- pregnancy complications and adverse perinatal outcome. PLoS One. 2014;9(8):e104755.

Cite this article as: Sengodan SS, Palanivelu A, Pandian A. A study on perinatal outcomes in antenatal mothers with abnormal pulmonary function tests. Int J Reprod Contracept Obstet Gynecol 2018;7:2724-7. 